\title{
Explaining variation in perceived team effectiveness: results from eleven quality improvement collaboratives
}

\author{
Mathilde MH Strating and Anna P Nieboer
}

\begin{abstract}
Aims and objectives. Explore effectiveness of 11 collaboratives focusing on 11 different topics, as perceived by local improvement teams and to explore associations with collaborative-, organisational- and team-level factors.

Background. Evidence underlying the effectiveness of quality improvement collaboratives is inconclusive and few studies investigated determinants of implementation success. Moreover, most evaluation studies on quality improvement collaboratives are based on one specific topic or quality problem, making it hard to compare across collaboratives addressing different topics. Design. A multiple-case cross-sectional study.

Methods. Quality improvement teams in 11 quality improvement collaboratives focusing on 11 different topics. Team members received a postal questionnaire at the end of each collaborative. Of the 283 improvement teams, 151 project leaders and 362 team members returned the questionnaire.

Results. Analysis of variance revealed that teams varied widely on perceived effectiveness. Especially, members in the Prevention of Malnutrition and Prevention of Medication Errors collaboratives perceived a higher effectiveness than other groups. Multilevel regression analyses showed that educational level of professionals, innovation attributes, organisational support, innovative culture and commitment to change were all significant predictors of perceived effectiveness. In total, $27.9 \%$ of the individual-level variance, $57.6 \%$ of the team-level variance and $80 \%$ of the collaborative-level variance could be explained. Conclusion. The innovation's attributes, organisational support, an innovative team culture and professionals' commitment to change are instrumental to perceived effectiveness. The results support the notion that a layered approach is necessary to achieve improvements in quality of care and provides further insight in the determinants of success of quality improvement collaboratives.

Relevance to clinical practice. Understanding which factors enhance the impact of quality improvement initiatives can help professionals to achieve breakthrough improvement in care delivery to patients on a wide variety of quality problems.
\end{abstract}

Key words: effectiveness, innovative culture, long-term care, nurses, nursing, patient safety, quality improvement collaborative

Accepted for publication: 1 November 2011

\section{Introduction}

Quality improvement collaboratives (QICs) are increasingly being used to improve quality of care. The Breakthrough method developed by the Institute for Healthcare Improvement (2003) has been one of the major instruments put to use in such collaboratives. In Breakthrough QICs, teams from different organisations join forces to improve care on a certain topic within a set time-frame, steered and supported by a faculty team. These teams will develop and implement improvement actions geared to their own organisations and client groups. Best practices or evidence-based interventions are the usual starting points and teams will learn about these at national conferences organised to this purpose. QICs are
Authors: Mathilde MH Strating, PhD, Assistant Professor, Institute of Health Policy and Management, Erasmus University Rotterdam; Anna P Nieboer, PhD, Associate Professor, Institute of Health Policy and Management, Erasmus University Rotterdam, Rotterdam, The Netherlands
Correspondence: Mathilde MH Strating, Assistant Professor, Erasmus University Rotterdam, Institute of Health Policy and Management, PO Box 1738, 3000 DR, Rotterdam, The Netherlands. Telephone: +31 104088557 .

E-mail: strating@bmg.eur.nl 
expected to enhance quality and efficiency of care by acting as a 'learning laboratory' stimulating and implementing innovations.

The evidence underlying the effectiveness of QICs is inconclusive (Leatherman 2002, Ovretveit 2002, Cretin et al. 2004, Schouten et al. 2008) and few studies investigated determinants of success (Mills \& Weeks 2004, Neily et al. 2005, Dückers et al. 2009). Moreover, most evaluation studies on QICs are based on one specific topic, making it hard to compare across collaboratives addressing different topics. The objective of our study is to explore effectiveness of 11 collaboratives focusing on 11 different topics, as perceived by local improvement teams and to explore associations with collaborative-, organisational- and teamlevel factors. The results contribute to a better insight into the mechanisms underlying QICs and factors that enhance success.

To understand the operating mechanism of QICs, the 'chain of action' framework developed by Cretin et al. (2004) is used, which suggests a layered approach is needed to improve quality. The proposed chain of action begins with participating teams and their environment, the latter comprising the organisational context and the broader context of the collaborative itself. To explain perceived effectiveness, we examine collaborative-level factors, the organisational context of the team and team-level factors.

At the collaborative level, several conditions should be in place for teams to be effective. First, we hypothesise that if new working methods are perceived by professionals as relatively beneficial, compatible with norms and values, easy to learn and implement, allow for experimentation and have observable results, the implementation process is expected to be more successful (Rogers 1995). Second, it is expected that stimulating participants' improvement efforts requires (1) a challenging and achievable collaborative target, (2) appropriate measures and usable monitoring tools that help teams make stepwise changes guided by measured results and keep them focused on the collaborative target (Øvretveit 2002, Øvretveit \& Gustafson 2002, Øvretveit et al. 2002, Dückers et al. 2009) and (3) program management support (Benn et al. 2009, Dückers et al. 2009, Nembhard 2009).

According to the 'chain of action' framework, commitment to quality improvement, organisational support and organisational culture are considered important organisationallevel conditions (Cretin et al. 2004, Lin et al. 2005). The more organisations involve their teams with quality improvement activities, the more the professionals will be committed to implementing changes and the more positive their perceptions of effectiveness will be. Also, organisational support in terms of leadership and active involvement of top manage- ment motivates professionals to achieve improvement (Gustafson et al. 2003, Mills \& Weeks 2004, Dückers et al. 2009, Kaplan et al. 2010). Culture conveys the norms, values, beliefs and behaviours of an organisation, reflecting 'how we do things around here'. The competing values framework distinguishes four types of culture: group (teamwork and participation), developmental (risk-taking, innovation and change), hierarchical (rules, regulations and bureaucracy) and rational (efficiency, goal attainment and achievement) (Zammuto et al. 2000, Shortell et al. 2004). Some studies suggest that organisations are most effective when a group culture is dominant (Lin et al. 2005). Shortell et al. (2004), however, suggest that each of the four types of cultures may contribute to effective quality improvement. Our hypothesis therefore is that the relative balance among the four culture types is associated with perceived effectiveness.

On the team level, or workgroup level as it is called in the 'chain of action' framework, compositional characteristics such as team size, educational level and presence of management have been found to play a role (Fried et al. 2000, Shortell et al. 2004). But also commitment to change and innovative culture are expected to be key determinants (Lin et al. 2005, Lemmens et al. 2009). Professionals who (1) are committed to change, (2) value the outcomes associated with successful implementation of changes in care processes and (3) believe that effort and implementation will lead to the targeted outcomes are key to successful improvement of quality of care. Innovative culture, conceptualised as social expectations of team members, may be more or less conducive to creativity and can facilitate implementation by generating social approval when working together effectively and acting quickly (Caldwell \& O'Reilly 2003). To conclude, we expect that differences in perceived effectiveness can be explained by the aforementioned collaborative-, organisational- and team-level characteristics.

\section{Methods}

\section{Setting and design}

This multiple-case cross-sectional study included quality improvement teams participating between 2006-2009 in 11 QICs which were part of a national Dutch program called 'Care for Better'. Each collaborative focused on one specific quality topic. These were: pressure ulcers, ill-nutrition, prevention of sexual abuse, medication safety, fall prevention, problem behaviour, client autonomy and control, social participation, recovery-oriented care, somatic comorbidity of psychiatric clients and outreach care (Table 1 and Strating et al. 2008, 2011). Organisations from the following sectors 


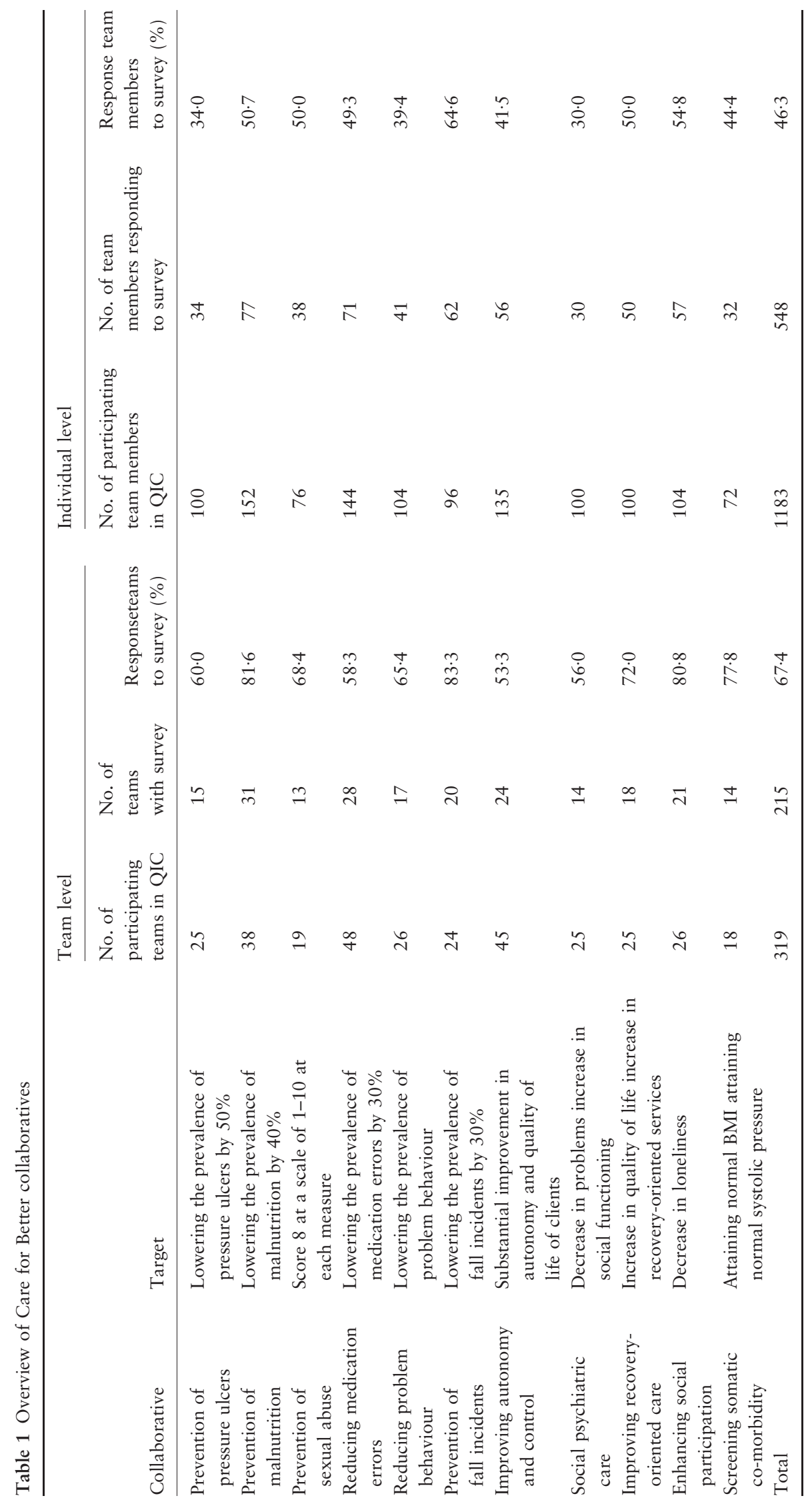


participated: nursing homes, residential care homes, home care, care for people with a mental handicap and care for people with a physical disability.

Program management was in the hands of the long-term care knowledge institute Vilans and it was commissioned by ZonMw, the main funding agency of health research in the Netherlands. As a research team, we were asked to describe the processes and effects of the collaboratives for clients and participating teams and to describe which interventions were actually carried out.

\section{Set up of the quality improvement collaboratives}

Each collaborative was led by a faculty team consisting of a program leader and other experts on the selected quality improvement topic. The improvement teams from the participating organisations were invited to attend four national conferences offering workshops and sessions where questions could be posed to other teams or to experts. The improvement teams developed and executed their interventions under the guidance of process counsellors. They used the Plan-Do-Study-Act cycle: carrying out small scale actions, measuring if the actions led to the expected outcomes and, if not, adjusting the actions.

\section{Data collection and measures}

As part of a larger evaluation study, team members received a postal questionnaire within one week after the last collaborative conference. Teams typically comprised five members, one of which was team leader. In total, 548 team members (about $46 \%$, on average 2.6 per team) returned a questionnaire (see for response per collaborative Table 1). These 548 respondents represented 215 teams of the 319 participating teams (about $67 \%$ at the team level).

The questionnaire mostly consisted of existing validated measurements instruments that have been used before in quality improvement projects (Appendix). Most instruments were validated in health care and extensively tested in previous studies. Internal consistency of each scale based on our study results is represented by Cronbach's alpha and is included in Table 2. Scores on all items of a scale were summed and divided by the number of items and higher scores indicate a higher degree of the underlying concept.

\section{Dependent variable}

Perceived team effectiveness was assessed by four questions, using a five-point response scale (Lemieux-Charles et al. 2002, Lemieux-Charles \& McGuire 2006). These questions
Table 2 Overview of theoretical constructs and instruments per variable

\begin{tabular}{|c|c|c|c|c|}
\hline & $\begin{array}{l}\text { No. of } \\
\text { items }\end{array}$ & $\begin{array}{l}\text { Potential } \\
\text { range }\end{array}$ & $\begin{array}{l}\text { Actual } \\
\text { range }\end{array}$ & $\begin{array}{l}\text { Cronbach's } \\
\text { alpha }\end{array}$ \\
\hline Perceived effectiveness & 4 & $1-5$ & $1 \cdot 25-5 \cdot 0$ & $0 \cdot 82$ \\
\hline Innovation's attributes & 10 & $1-5$ & $2 \cdot 6-5 \cdot 0$ & $0 \cdot 68$ \\
\hline $\begin{array}{l}\text { Program management } \\
\text { expertise }\end{array}$ & 5 & $1-7$ & $2 \cdot 5-7 \cdot 0$ & $0 \cdot 86$ \\
\hline Advisor support & 4 & $1-7$ & $1 \cdot 5-7 \cdot 0$ & $0 \cdot 84$ \\
\hline Achievability & 4 & $1-7$ & $1 \cdot 75-7 \cdot 0$ & $0 \cdot 77$ \\
\hline Challenging targets & 1 & $1-7$ & $1 \cdot 0-7 \cdot 0$ & \\
\hline Measurability & 4 & $1-7$ & $1 \cdot 0-7 \cdot 0$ & $0 \cdot 86$ \\
\hline $\begin{array}{l}\text { Quality improvement } \\
\text { commitment }\end{array}$ & 8 & $1-5$ & $2 \cdot 27-5 \cdot 0$ & $0 \cdot 85$ \\
\hline Organisational support & 13 & $1-7$ & $1-7$ & $0 \cdot 90$ \\
\hline Cultural balance & 20 & $0-1$ & $0-0 \cdot 82$ & \\
\hline Innovative culture & 15 & $1-5$ & $1 \cdot 93-3 \cdot 62$ & $0 \cdot 81$ \\
\hline Commitment to change & 18 & $1-245$ & $44-245$ & \\
\hline
\end{tabular}

assessed the extent to which each team member: (1) believed the team's overall performance met expectations, (2) was satisfied with his/her experience as a team member, (3) felt positive about their experience and (4) would be willing to work in a similar team in the future. A higher score indicates a higher level of perceived effectiveness.

\section{Independent variables at the collaborative level}

- Innovation attributes were assessed with 10 items on the innovation's relative benefit, compatibility, complexity and observability (Vos et al. 2008). Items were rated by each team member on a scale of 1 (totally disagree)-5 (totally agree) and summed to form one score.

- Program management expertise on breakthrough methodology and the collaborative topic, provision of information and advice was rated by project leaders with five items on a scale of 1-7 (Dückers et al. 2008). An example statement: 'program management had sufficient expertise on the improvement methods'.

- Advisor's support was assessed by four items. Project leaders rated the extent to which their advisor gave advice that was good and specific to the team's needs and problems (Dückers et al. 2008). Four items were rated on a scale of 1-7. An example statement: 'Our advisor was sufficiently responsive in the design of our action plan, implementation of improvement actions and measurements'.

- Achievability was assessed by four statements. Example statements are: 'collaborative targets are achievable' and 'program management made clear how to achieve collaborative targets' (Dückers et al. 2008). Rating was on a 
seven-point scale ranging from 'strongly disagree' to 'strongly agree'. Higher scores indicated that team leaders perceived a higher degree of achievability of the collaborative's targets.

- Challenging targets was assessed by project leaders who rated whether 'Program management set high expectations with regard to performance and improvement possibilities' (Dückers et al. 2008). Team leaders rated this statement on a seven-point scale ranging from 'strongly disagree' to 'strongly agree'.

- Measurability was assessed by four statements. Example statements are: 'measuring indicators helps to monitor progress' and 'there were clear agreements on measuring central indicators' (Dückers et al. 2008). Rating was on a seven-point scale ranging from 'strongly disagree' to 'strongly agree'. Higher scores indicated perception of a higher degree of measurability.

\section{Independent variables at the organisational level}

- Quality improvement commitment was assessed in the project leaders' survey with eight items formulated by the European foundation for quality management (Shortell et al. 1995). Rating was on a five-point scale ranging from 'strongly disagree' to 'strongly agree'. Example statements were 'Realising improvements is rewarded in this organisation' and 'Our board of directors is actively involved in quality improvement'.

- Organisational support was assessed by 13 items of existing questionnaires (RAND 1999) on availability of time and means and on the degree of encouragement from top management. Rating was on a seven-point scale ranging from 'strongly disagree' to 'strongly agree'. An example statement: 'Senior management encouraged staff to improve their performance'.

- Organisational culture was assessed in line with the competing values framework (Shortell et al. 1995, Zammuto et al. 2000). Team members distributed 100 points across four sets of organisational statements (representing the culture types) according to descriptions that best fit their organisation. The Blau Index of heterogeneity (Blau 1977) was calculated to assess the level of balance between the four culture types. A score of 1 indicates that points were apportioned in a $25 / 25 / 25 / 25$ pattern and indicates an optimal balance.

\section{Independent variables at the team level}

- Team composition characteristics were based on individual socio-demographic characteristics. Education level was assessed by a 0-7 point ordinal scale, higher scores indicating a higher educational level. A variable indicating whether a manager was part of the team was computed. Project leaders were asked whether any changes (dropouts or new team members) occurred.

- Innovative culture of the team was assessed by 15 items of the Group Innovation Inventory (Caldwell \& O'Reilly 2003, Strating \& Nieboer 2010, Nieboer \& Strating 2011). Respondents were asked to answer statements on a five-point scale ranging from 'strongly disagree' to 'strongly agree'. Higher scores indicated a more innovative culture. An example statement: 'The attitude around here is that when you are trying new things, mistakes are a normal part of the job'.

- Commitment to change was assessed by 28 items with a seven-point rating scale based on the expectancy measurement for motivation developed by Vroom (1995). Three subscales were computed: expectancy (perceived probability that effort will lead to good performance), instrumentality (perceived probability that good performance will lead to desired outcomes) and valence (value that an individual personally places on these outcomes). A composite measure was calculated as the product of valence, instrumentality and expectancy. Example items are 'how important do you find making changes that improve processes of care?', 'success in implementing changes in care will help improve quality of care' and 'exerting effort will help implement changes in care for clients'.

\section{Analysis}

Owing to missing data on one or more of the variables, a sample of 513 was used for the analyses. We examined Spearman or Pearson correlations. Because of the hierarchical structure of the data (individuals are nested within teams and within collaboratives), a normal regression design would lead to estimation errors. We thus employed multi-level techniques (mixed models option sPSs 17; SPSS Inc., Chicago, IL, USA). We first estimated an empty model (0), which reflected variation in the intercept. To assess the extent to which variance should be ascribed to the team or collaborative rather than individual level, collaboratives served as level-3 and teams as level-2 units (model 1). In the models thereafter, we entered the independent variables as fixed effects in separate steps. As individual socio-demographic and team composition characteristics are expected to influence perceived effectiveness as well as other independent variables, these were included first. Following the theoretical model, collaborative-, organisation- and team-level variables were entered in the separate steps. Results were considered statistically significant when two-sided $p$-values were $\leq 0 \cdot 05$. Deviance tests or likelihood ratio tests compared the relative 
fit of the different models. The difference in deviance of two nested models has a chi-square distribution with degrees of freedom equal to the number of extra parameters in the larger model.

\section{Results}

\section{Sample characteristics}

Respondents had a mean age of 44 and were mostly female $(72.9 \%)$. About $53 \%$ had completed tertiary education, $15 \%$ had a university degree. About $85 \%$ had been working for more than three years in the organisation and $66.7 \%$ worked more than 29 hours per week. Teams consisted of medical assistants $(6 \cdot 1 \%)$, nurses $(25 \cdot 8 \%)$, social workers $(7 \cdot 8 \%)$, medical specialists $(7 \cdot 3 \%)$, paramedical professionals $(9 \cdot 2 \%)$, quality staff $(10 \cdot 9 \%)$ and lower and middle managers $(32 \cdot 9 \%)$.

\section{Descriptive statistics}

Table 3 provides descriptive statistics (mean, standard deviation or percentages) of all variables. Mean scores on the collaborative-level variables were moderate with mean score varying between $4 \cdot 01$ and $5 \cdot 34$ on a seven-point scale. With respect to organisational factors, commitment to quality improvement had a mean of 3.81 on a five-point scale, indicating a relatively high rate of professional involvement in quality improvement and team member training. The mean score on organisational support was relatively low (4.05 on a seven-point scale). With respect to cultural balance, a mean of 0.67 on a $0-1$ range indicated that most respondents perceived a moderate balance between the four types of culture in their organisation. At the team level, innovative culture was moderate with a mean of 3.62 (on five-point scale) and commitment to change was relatively low with a mean of 123.52 compared with the theoretical range of $1-245$.

Perceived effectiveness varied between the 11 collaboratives (Table 4). High average scores were found especially in the Prevention of Malnutrition and Prevention of Medication Errors collaboratives. Reducing Problem Behaviour and Social Psychiatric Care scored relatively low on perceived effectiveness.

\section{Associations between independent and dependent variables}

Frontline professionals and respondents with a higher educational level scored lower on perceived effectiveness
Table 3 Descriptive statistics and correlation with perceived effectiveness $\left(n_{\text {teams }}=215\right)\left(n_{\text {individual }}=513\right)$

\begin{tabular}{|c|c|c|c|}
\hline $\begin{array}{l}\text { Demographic } \\
\text { characteristics }\end{array}$ & $n$ & $\begin{array}{l}\% \text { or } \\
\text { mean }(\mathrm{SD})\end{array}$ & Correlation \\
\hline \multicolumn{4}{|l|}{ Gender } \\
\hline 0 male & 139 & $27 \cdot 1 \%$ & \multirow[t]{2}{*}{$0 \cdot 02$} \\
\hline 1 female & 374 & $72 \cdot 9 \%$ & \\
\hline \multicolumn{4}{|l|}{ Position } \\
\hline 0 manager/quality staff & 222 & $43 \cdot 3 \%$ & \multirow[t]{2}{*}{$-0.09 *$} \\
\hline 1 frontline professionals & 219 & $42 \cdot 7 \%$ & \\
\hline Age & 513 & $44 \cdot 20(9 \cdot 69)$ & $0 \cdot 02$ \\
\hline Educational level & 513 & $5 \cdot 47(1 \cdot 23)$ & $-0 \cdot 12 *$ \\
\hline \multicolumn{4}{|c|}{ Team composition characteristics } \\
\hline \multicolumn{4}{|l|}{ Stable team } \\
\hline 0 no & 154 & $71 \cdot 6 \%$ & \multirow[t]{2}{*}{$-0 \cdot 14$} \\
\hline 1 yes & 61 & $28 \cdot 4 \%$ & \\
\hline \multicolumn{4}{|l|}{ Manager in the team } \\
\hline 0 no & 94 & $43 \cdot 7 \%$ & \multirow[t]{2}{*}{$0 \cdot 17^{*}$} \\
\hline 1 yes & 121 & $56 \cdot 3 \%$ & \\
\hline$\%$ females in the team & 215 & $73.0(33.7)$ & 0.09 \\
\hline $\begin{array}{l}\text { Mean educational level } \\
\text { of the team }\end{array}$ & 215 & $5.54(0.90)$ & $-0 \cdot 13$ \\
\hline $\begin{array}{l}\% \text { tertiary education } \\
\text { of the team }\end{array}$ & 215 & $70 \cdot 2(34 \cdot 2)$ & $-0 \cdot 13$ \\
\hline \multicolumn{4}{|l|}{ Collaborative-level variables } \\
\hline Innovation's attributes & 513 & $4.01(0 \cdot 45)$ & $0 \cdot 44 * *$ \\
\hline $\begin{array}{l}\text { Program management } \\
\text { expertise }\end{array}$ & 215 & $5.34(0.96)$ & $0 \cdot 15 * *$ \\
\hline Advisor support & 215 & $4.95(1.42)$ & $0 \cdot 11 *$ \\
\hline Achievability & 215 & $5.01(0.95)$ & $0 \cdot 17 * *$ \\
\hline Challenging targets & 215 & $4 \cdot 24(1 \cdot 32)$ & $0 \cdot 02$ \\
\hline Measurability & 215 & $4.98(1.17)$ & $0 \cdot 13 * *$ \\
\hline \multicolumn{4}{|l|}{ Organisation-level variables } \\
\hline $\begin{array}{l}\text { Quality improvement } \\
\text { commitment }\end{array}$ & 215 & $3 \cdot 81(0 \cdot 60)$ & $0 \cdot 08$ \\
\hline Organisational support & 513 & $4.05(1 \cdot 10)$ & $0 \cdot 42 * *$ \\
\hline Cultural balance & 513 & $0.67(0.09)$ & $-0 \cdot 07$ \\
\hline \multicolumn{4}{|l|}{ Team-level variables } \\
\hline Innovative culture & 513 & $3.62(0 \cdot 41)$ & $0 \cdot 48 * *$ \\
\hline Commitment to change & 513 & $123 \cdot 52(39 \cdot 13)$ & $0 \cdot 35 *$ \\
\hline
\end{tabular}

Two-tailed $p$-values.

(Table 3). Teams with a manager in the team scored higher. Of the collaborative-level variables, all but challenging targets were significantly positively associated with perceived effectiveness. Of the organisational-level variables, only organisational support had a significant correlation. Both team-level variables were significantly correlated with perceived effectiveness, innovative culture having the highest correlation coefficient of $0 \cdot 48$.

Table 5 shows the results of the multilevel regression analysis. The first empty model served as a baseline with just intercepts. Model 1 shows that about 33\% of the variance 
Table 4 Descriptive statistics on perceived effectiveness for each collaborative

\begin{tabular}{lccc}
\hline & $n$ & Mean & SD \\
\hline Prevention of medication errors & 67 & 4.19 & 0.65 \\
Prevention of malnutrition & 72 & 4.16 & 0.67 \\
Improving recovery-oriented care & 48 & 4.01 & 0.71 \\
Prevention of fall incidents & 59 & 3.98 & 0.62 \\
Improving autonomy and control & 52 & 3.97 & 0.59 \\
Prevention of pressure ulcers & 31 & 3.95 & 0.59 \\
Enhancing social participation & 30 & 3.89 & 0.65 \\
Screening of somatic comorbidity & 52 & 3.78 & 0.71 \\
Prevention of sexual abuse & 36 & 3.81 & 0.79 \\
Reducing problem behaviour & 36 & 3.65 & 0.64 \\
Social psychiatric care & 30 & 3.43 & 0.89 \\
Total & 513 & 3.94 & 0.70 \\
\hline
\end{tabular}

Analysis of variance $F=4.51$ and $p=0 \cdot 000$.

could be attributed to differences between teams and 5\% to differences between collaboratives. Model 2 shows that respondent's educational level, innovation's attributes, organisational support, innovative team culture and commitment to change have positive effects on perceived effectiveness. In total, $27.9 \%$ individual-level variance, $57.6 \%$ team-level variance and $80 \%$ collaborative-level variance could be explained.

\section{Discussion}

The evidence underlying the effectiveness of QICs is inconclusive (Leatherman 2002, Ovretveit 2002, Cretin et al. 2004, Schouten et al. 2008) and few studies investigated determinants of implementation success (Mills \& Weeks 2004, Neily et al. 2005, Dückers et al. 2009). Moreover, most evaluation studies are based on one specific topic, making it hard to compare across collaboratives addressing different topics. The objective of our study was to explore effectiveness of 11 collaboratives focusing on 11 different topics, as perceived by local improvement teams and to explore associations with collaborative-, organisational- and

Table 5 Hierarchical linear multilevel analyses on perceived effectiveness $(n=513)$

\begin{tabular}{|c|c|c|c|c|c|c|c|c|c|c|c|c|}
\hline \multirow[b]{2}{*}{ Model } & \multicolumn{2}{|l|}{0} & \multicolumn{2}{|l|}{1} & \multicolumn{2}{|l|}{2} & \multicolumn{2}{|l|}{3} & \multicolumn{2}{|l|}{4} & \multicolumn{2}{|l|}{5} \\
\hline & B & SE & B & SE & B & SE & B & SE & B & $\mathrm{SE}$ & B & SE \\
\hline Constant & $0 \cdot 01$ & $0 \cdot 05$ & $-0 \cdot 06$ & $0 \cdot 09$ & $0 \cdot 33$ & $0 \cdot 36$ & $0 \cdot 64^{\$}$ & $0 \cdot 34$ & $0 \cdot 58^{\$}$ & $0 \cdot 33$ & $0.93 * *$ & $0 \cdot 31$ \\
\hline Gender & & & & & $0 \cdot 07$ & $0 \cdot 11$ & $0 \cdot 00$ & $0 \cdot 10$ & $0 \cdot 05$ & $0 \cdot 10$ & $0 \cdot 00$ & 0.09 \\
\hline Age & & & & & $0 \cdot 00$ & $0 \cdot 00$ & $0 \cdot 00$ & $0 \cdot 00$ & $0 \cdot 00$ & $0 \cdot 00$ & $-0 \cdot 01$ & $0 \cdot 00$ \\
\hline Educational level & & & & & $-0.07^{\$}$ & 0.09 & $-0 \cdot 10 * *$ & $0 \cdot 04$ & $-0 \cdot 09 * *$ & $0 \cdot 04$ & $-0 \cdot 11^{* *}$ & $0 \cdot 03$ \\
\hline Position & & & & & $-0 \cdot 13$ & 0.09 & $-0 \cdot 09$ & $0 \cdot 09$ & $-0 \cdot 05$ & $0 \cdot 08$ & $-0 \cdot 09$ & $0 \cdot 08$ \\
\hline Stable team & & & & & $0 \cdot 12$ & $0 \cdot 13$ & $0 \cdot 16$ & $0 \cdot 12$ & $0 \cdot 02$ & $0 \cdot 12$ & $-0 \cdot 05$ & $0 \cdot 11$ \\
\hline \multicolumn{13}{|l|}{ Collaborative-level variables } \\
\hline Innovation's attributes & & & & & & & $0 \cdot 34 * *$ & $0 \cdot 05$ & $0 \cdot 29 * *$ & $0 \cdot 05$ & $0 \cdot 24 * *$ & $0 \cdot 04$ \\
\hline Program management expertise & & & & & & & $0 \cdot 12$ & $0 \cdot 11$ & $0 \cdot 03$ & $0 \cdot 11$ & $-0 \cdot 04$ & $0 \cdot 10$ \\
\hline Advisor support & & & & & & & -0.07 & $0 \cdot 09$ & $0 \cdot 02$ & 0.09 & $0 \cdot 05$ & 0.08 \\
\hline Achievability & & & & & & & $0 \cdot 14$ & 0.09 & $0 \cdot 12$ & 0.08 & $0 \cdot 14^{\$}$ & 0.07 \\
\hline Challenging targets & & & & & & & 0.06 & 0.06 & $0 \cdot 02$ & 0.06 & $0 \cdot 00$ & 0.06 \\
\hline Measurability & & & & & & & $-0 \cdot 01$ & $0 \cdot 07$ & $-0 \cdot 04$ & $0 \cdot 07$ & $-0 \cdot 06$ & 0.06 \\
\hline \multicolumn{13}{|l|}{ Organisation-level variables } \\
\hline Quality improvement commitment & & & & & & & & & & & $-0 \cdot 04$ & 0.06 \\
\hline Organisational support & & & & & & & & & & & $0 \cdot 18 * *$ & $0 \cdot 05$ \\
\hline Cultural balance & & & & & & & & & & & $-0 \cdot 06$ & $0 \cdot 04$ \\
\hline \multicolumn{13}{|l|}{ Team-level variables } \\
\hline Innovative culture & & & & & & & & & & & $0 \cdot 24 * *$ & $0 \cdot 05$ \\
\hline Commitment to change & & & & & & & & & & & $0 \cdot 16 * *$ & $0 \cdot 04$ \\
\hline$-2 \log$ likelihood & $1264 \cdot 51$ & & $1214 \cdot 68$ & & $1042 \cdot 63$ & & $922 \cdot 37$ & & $954 \cdot 21$ & & $922 \cdot 04$ & \\
\hline Variance individual level & $0 \cdot 97$ & $0 \cdot 06$ & $0 \cdot 61$ & $0 \cdot 05$ & $0 \cdot 55$ & $0 \cdot 05$ & $0 \cdot 51$ & $0 \cdot 05$ & $0 \cdot 48$ & $0 \cdot 05$ & $0 \cdot 44$ & $0 \cdot 05$ \\
\hline Variance team level & & & $0 \cdot 33$ & $0 \cdot 07$ & $0 \cdot 36$ & $0 \cdot 08$ & $0 \cdot 22$ & 0.06 & $0 \cdot 19$ & $0 \cdot 05$ & $0 \cdot 14$ & $0 \cdot 05$ \\
\hline Variance collaborative level & & & $0 \cdot 05$ & $0 \cdot 04$ & $0 \cdot 03$ & $0 \cdot 03$ & $0 \cdot 03$ & $0 \cdot 03$ & $0 \cdot 01$ & $0 \cdot 02$ & $0 \cdot 01$ & $0 \cdot 02$ \\
\hline Explained individual level & & & & & & & & & & & $27 \cdot 9 \%$ & \\
\hline Explained variance team level & & & & & & & & & & & $57 \cdot 6 \%$ & \\
\hline Explained variance collaborative level & & & & & & & & & & & $80 \cdot 0 \%$ & \\
\hline
\end{tabular}

$* p<0.05 * p<0.01 \$ 0.05>p<0.10$, all two-sided tests.

${ }^{1}(($ variance individual-level model 1 - variance individual-level final model $) /$ variance individual-level model 1$) * 100=0 \cdot 61-0 \cdot 44 /$ $0 \cdot 61 * 100=27 \cdot 9 \%$. 
team-level factors. The results partly supported the theoretically proposed associations. As suggested by several authors, the nature of topic or quality problem addressed is critically important to a collaborative's effectiveness (Øvretveit \& Gustafson 2002, Wilson et al. 2003). Respondents in the Prevention of Malnutrition and Prevention of Medication Errors collaboratives perceived effectiveness as considerably higher than respondents in other collaboratives, those in Reducing Problem Behaviour and Social Psychiatric Care perceived effectiveness as considerably lower.

In preparing and organising a QIC program, managers should carefully consider the type of quality problem or topic addressed and researchers investigating effectiveness of QICs should also take this into account. At the collaborative level, the innovation's attributes are key in explaining implementation success. The more the new working methods were perceived by professionals as - having relative benefit, being compatible with norms and values, not difficult to learn and implement and leading to observable results - the more the implementation process was perceived as successful. In contrast with previous studies (Øvretveit 2002, Øvretveit \& Gustafson 2002, Øvretveit et al. 2002, Benn et al. 2009, Dückers et al. 2009, Nembhard 2009), the other collaborative-level factors - program management expertise, advisor support, achievability, challenging targets and measurability - were not significant predictors. Although most of these variables showed significant associations with perceived effectiveness in the univariate analyses, the associations disappeared in the multivariate analyses owing to the strong effect of the innovation's attributes.

At the organisational level, the findings suggest that for teams to perceive a higher impact of their improvement efforts, organisational support is crucial. In line with previous studies (Gustafson et al. 2003, Mills \& Weeks 2004, Dückers et al. 2009), organisational support - conceptualised as making time, finances, means and instruments available and having a manager who shows interest, coaches and encourages professionals - is important to achieve improvement. In contrast with previous studies (Meterko et al. 2004, Shortell et al. 2004, Lin et al. 2005, Hann et al. 2007), the other organisational-level variables, quality improvement commitment and organisational culture, were not identified as determinants of perceived effectiveness.

Commitment to change and innovative culture are both significant predictors of perceived effectiveness on the team level. Professionals who attach importance to the outcomes of quality improvement and believe they can achieve them are associated with higher perceived effectiveness. Innovative culture, however, was the stronger predictor. Teams with high social expectations - trying new ways of doing things, taking risks, tolerating mistakes - facilitate implementation.

\section{Limitations}

The cross-sectional design hampered our ability to draw causal inferences. Our results establish a significant association, which is an important step that prompts further studies to identify directionality. Second, the overall moderate response on the evaluation survey and the rather low number of respondents per team (2.6) may have led to some selection bias. During the collaborative program, many team members held other jobs or left the organisation. Given the dynamics in the field with new (compulsory) policies, reorganisations or mergers, not many respondents were available for this study. Third, we used self-reported instruments to assess organisational- and team-level factors and perceived effectiveness. Professionals' perceptions of effectiveness may have been influenced by expectations and positive feelings of working together. Although such a measure can introduce bias, the considerable variation between teams and collaboratives left room for explanation by organisational- and team-level factors.

Unfortunately, no single measure for objective effectiveness could be computed across all 11 collaboratives owing to the diversity in topic, content and outcome indicators. Neglecting the content of the indicator and gathering the different indicators together would lead to misleading results. We thus used the perceived effectiveness of team members as an indicator of the collaboratives' overall impact. Other accomplishments and effects not measured by outcome indicators may well be perceived, especially in the context of service delivery. Team members, for example, may have noticed how patients benefited or how professionals learned new working practices and routines. Distinguishing a subjective part as a conceptualisation of effectiveness allows us to compare the effectiveness of collaboratives that address different types of problems. For future research, it would be interesting to investigate to what extent perceived effectiveness is related to changes in objective outcome indicators and what different determinants of success may play a role. Although these general limitations may have somewhat influenced the reported results, they allowed us to compare a wide range of QICs, a major strength of the study.

\section{Conclusion}

The results support the notion that a layered approach is necessary to achieve improvements in quality of care and 
provide further insight in the determinants of success of QICs. By evaluating 11 different QICs, our study provides insight in how collaborative-, organisational- and team-level factors may play a role in perceived effectiveness of different collaboratives. The innovation's attributes, organisational support, an innovative team culture and professionals' commitment to change are instrumental to perceived effectiveness.

\section{Relevance to clinical practice}

Understanding which factors enhance the impact of quality improvement initiatives can help professionals to achieve breakthrough improvement in care delivery to patients on a wide variety of quality problems.

\section{Acknowledgement}

The authors thank the participating improvement teams and questionnaire respondents.

\section{Contributions}

Study design: MMHS, APN; data collection and analysis: MMHS, APN and manuscript preparation: MMHS, APN.

\section{Conflict of interest}

The author(s) declare that they have no conflict of interests.

\section{Ethical approval}

As the quality improvement initiatives were part of daily practice and were initiated and implemented by health care organisations and not by the evaluation research team, no ethics approval was required in the current ethical regime in The Netherlands.

\section{Funding}

The Care for Better program and evaluation study are funded by the Netherlands Organization for Health Research and Development (ZonMw grantnr 5942 and 60-60900-96-005). The evaluation study researchers are independent of the funding organisation.

\section{References}

Benn J, Burnett S, Parand A, Pinto A, Iskander S \& Vincent C (2009) Perceptions of the impact of a large-scale collaborative improvement programme: experience in the UK Safer Patients Initiative. Journal of Evaluation in Clinical Practice 15, 524-540.

Blau PM (1977) Inequality and Heterogeneity: A Primitive Theory of Social Structure. Free Press, New York, NY.

Caldwell DF \& O'Reilly CA (2003) The determinants of team-based innovation in organisations. The role of social influence. Small Group Research 34, 497-517.

Cretin S, Shortell SM \& Keeler EB (2004) An evaluation of collaborative interventions to improve chronic illness care. Framework and study design. Evaluation Review 28, 28-51.

Dückers MLA, Wagner C \& Groenewegen PP (2008) Developing and testing an instrument to measure the presence of conditions for successful implementation of quality improvement collabora- tives. BMC Health Services Research 8, 172.

Dückers MLA, Spreeuwenberg P, Wagner C \& Groenewegen P (2009) Exploring the black box of quality improvement collaboratives: modelling relations between conditions, applied changes and outcomes. Implementation Science 4, 74.

Fried B, Rundall T \& Topping S (2000) Groups and teams in health service organisations. Health Care Management: Organisation Design and Behaviour, 154-190.

Gustafson DH, Sainfort F, Eichler M, Adams L, Bisognano M \& Steudel $\mathrm{H}$ (2003) Developing and testing a model to predict outcomes of organizational change. Health Services Research 38, 751-776.

Hann M, Bower P, Campbell S, Marshall M \& Reeves D (2007) The association between culture, climate and quality of care in primary health care teams. Family Practice 24, 323-329.
Institute for Healthcare Improvement (2003) The Breakthrough Series: IHI's Collaborative Model for Achieving Breakthrough Improvement. IHI, Cambridge, MA.

Kaplan HC, Brady PW, Dritz MC, Hooper DK, Linam WM, Froehle CM \& Margolis P (2010) The influence of context on quality improvement success in health care: a systematic review of the literature. The Milbank Quarterly 88, 500-559.

Leatherman S (2002) Optimizing quality collaboratives. Quality and Safety in Health Care 11, 307.

Lemieux-Charles L \& McGuire WL (2006) What do we know about health care team effectiveness? A review of the literature. Medical Care Research and Review 63, 263-300.

Lemieux-Charles L, Murray M, Baker GR, Barnsley J, Tasa K \& Ibrahim SA (2002) The effects of quality improvement practices on team effectiveness: a 
mediational model. Journal of Organizational Behavior 23, 533-553.

Lemmens K, Strating M, Huijsman R \& Nieboer A (2009) Professional commitment to changing chronic illness care: results from disease management programmes. International Journal for Quality in Health Care 21, 233242.

Lin MK, Marsteller JA, Shortell SM, Mendel P, Pearson M, Rosen M \& Wu SY (2005) Motivation to change chronic illness care: results from a national evaluation of quality improvement collaboratives. Health Care Management Review 30, 139-156.

Meterko M, Mohr DC \& Young GJ (2004) Teamwork culture and patient satisfaction in hospitals. Medical Care 42, 492-498.

Mills PD \& Weeks WB (2004) Characteristics of successful quality improvement teams: lessons from five collaborative projects in the VHA. Joint Commission Journal on Quality and Safety 30, 152162.

Neily J, Howard K, Quigley P \& Mills PD (2005) One-year follow-up after a collaborative breakthrough series on reducing falls and fall-related injuries. Joint Commission Journal on Quality and Patient Safety 31, 275-285.

Nembhard IM (2009) Learning and improving in quality improvement collaboratives: which collaborative features do participants value most? Health Services Research 44, 359-378.

Nieboer AP \& Strating MMH (2011) Innovative culture in long-term care settings: the influence of organizational characteristics. Health Care Management Review, in press.
Ovretveit J (2002) Action Evaluation of Health Programmes and Changes: A Handbook for a User-Focused Approach. Radcliffe Medical Press, Oxford.

Øvretveit J (2002) How to run an effective improvement collaborative. International Journal for Health Care Quality Assurance 15, 192-196.

Øvretveit J \& Gustafson D (2002) Evaluation of quality improvement programmes. Quality and Safety in Health Care 11, 270-275.

Øvretveit J, Bate P, Cleary P, Cretin S, Gustafson D, McInnes K, McLeod H, Molfenter T, Plsek P \& Robert G (2002) Quality collaboratives: lessons from research. Quality and Safety in Health Care 11, 345-351.

RAND (1999) Improving Chronic Illness Care Evaluation. Healthcare Organization Survey for Breakthrough Series (BTS) Team Members. RAND, Santa Monica, CA.

Rogers EM (1995) Diffusion of Innovation. The Free Press, New York, NY.

Schouten LMT, Hulscher M, Everdingen JJE, Huijsman R \& Grol R (2008) Evidence for the impact of quality improvement collaboratives: systematic review. British Medical Journal 336, 1491-1494.

Shortell SM, O’Brien JL, Carman JM, Foster RW, Hughes EF, Boerstler H \& O'Connor EJ (1995) Assessing the impact of continuous quality improvement/total quality management: concept versus implementation. Health Services Research 30, 377-401.

Shortell SM, Marsteller JA, Lin M, Pearson ML, Wu SY, Mendel P, Cretin S \& Rosen M (2004) The role of perceived team effectiveness in improving chronic illness care. Medical Care 42, 1040 1048.

Strating MMH \& Nieboer AP (2010) Norms for creativity and implementation in healthcare teams: testing the group innovation inventory. International Journal for Quality in Health Care 6, 1-8.

Strating MMH, Zuiderent-Jerak T, Nieboer AP \& Bal RA (2008) Evaluating the Care for Better Collaborative. Results of the First Year of Evaluation. Institute of Health Policy and Management, Rotterdam.

Strating MMH, Nieboer AP, ZuiderentJerak T \& Bal RA (2011) Creating effective quality improvement collaboratives: a multiple case study. Quality and Safety in Health Care 20, 344-350.

Vos L, Dückers M \& Wagner C (2008) Evaluation Better Faster Pillar 3: Results of an Improvement Programme for Hospitals. Nivel, Utrecht [in Dutch].

Vroom VH (1995) Work and Motivation. Jossey-Bass, Co., San Francisco.

Wilson T, Berwick DM \& Cleary PD (2003) What do collaborative improvement projects do? Experience from seven countries. Joint Commission Journal on Quality and Patient Safety 29, 85-93.

Zammuto RF, Gifford G \& Goodman EA (2000) Managerial ideologies, organisation culture and the outcomes of innovation: a competing values perspective. In The Handbook of Organizational Culture and Climate (Ashkanasy NM, Wilderom C \& Peterson MF eds). Sage Publications, Inc, Thousand Oaks, CA, pp. 261-278.

\section{Appendix}

\section{Measurement instruments}

\section{Perceived effectiveness}

Lemieux-Charles L, Murray M, Baker GR, et al. (2002) The effects of quality improvement practices on team effectiveness: a mediational model. Journal of Organizational Behavior 23, 533-553.

\begin{tabular}{|c|c|c|c|c|c|}
\hline \multirow[b]{2}{*}{ I am satisfied with my experience as a team member } & \multicolumn{3}{|c|}{ Strongly disagree } & \multicolumn{2}{|c|}{ Strongly agree } \\
\hline & 1 & 2 & 3 & 4 & 5 \\
\hline I feel positive about my experience in the team & 1 & 2 & 3 & 4 & 5 \\
\hline I am willing to work in a similar team in the future & 1 & 2 & 3 & 4 & 5 \\
\hline I believe the team's overall performance met (my) expectations & 1 & 2 & 3 & 4 & 5 \\
\hline
\end{tabular}




\section{Innovation attributes}

Vos L, Dückers M, Wagner C (2008) Evaluation Better Faster pillar 3: results of an improvement programme for hospitals [in Dutch].

The new improvement and working methods of Care for Better

\begin{tabular}{lrrrr}
\multicolumn{2}{c}{ Strongly disagree } & & \multicolumn{2}{c}{ Strongly agree } \\
1 & 2 & 3 & 4 & 5 \\
1 & 2 & 3 & 4 & 5 \\
1 & 2 & 3 & 4 & 5 \\
1 & 2 & 3 & 4 & 5 \\
1 & 2 & 3 & 4 & 5 \\
1 & 2 & 3 & 4 & 5 \\
1 & 2 & 3 & 4 & 5 \\
1 & 2 & 3 & 4 & 5 \\
1 & 2 & 3 & 4 & 5 \\
1 & 2 & 3 & 4 & 5 \\
\hline
\end{tabular}

\section{Program management expertise}

Dückers ML, Wagner C, Groenewegen PP (2008) Developing and testing an instrument to measure the presence of conditions for successful implementation of quality improvement collaboratives. BMC Health Serv Res 8, 172.

\begin{tabular}{|c|c|c|c|c|c|c|c|}
\hline \multirow{2}{*}{$\begin{array}{l}\text { Program management } \\
\text { Explained the improvement methods well }\end{array}$} & \multicolumn{4}{|c|}{ Strongly disagree } & \multicolumn{3}{|c|}{ Strongly agree } \\
\hline & 1 & 2 & 3 & 4 & 5 & 6 & 7 \\
\hline Provided clarity on the purpose and approach of the project & 1 & 2 & 3 & 4 & 5 & 6 & 7 \\
\hline Gave a sufficiently tailored instruction & 1 & 2 & 3 & 4 & 5 & 6 & 7 \\
\hline Had sufficient expertise on the quality improvement topic & 1 & 2 & 3 & 4 & 5 & 6 & 7 \\
\hline Had sufficient expertise on the improvement methods & 1 & 2 & 3 & 4 & 5 & 6 & 7 \\
\hline
\end{tabular}

\section{Advisor support}

Dückers ML, Wagner C, Groenewegen PP (2008) Developing and testing an instrument to measure the presence of conditions for successful implementation of quality improvement collaboratives. BMC Health Serv Res 8, 172.

\begin{tabular}{|c|c|c|c|c|c|c|c|}
\hline \multirow{2}{*}{$\begin{array}{l}\text { Our advisor } \\
\text { Had regular telephone contact }\end{array}$} & \multicolumn{4}{|c|}{ Strongly disagree } & \multicolumn{3}{|c|}{ Strongly agree } \\
\hline & 1 & 2 & 3 & 4 & 5 & 6 & 7 \\
\hline $\begin{array}{l}\text { Was sufficiently responsive in the design of our action plan, implementation } \\
\text { of improvement actions and measurements }\end{array}$ & 1 & 2 & 3 & 4 & 5 & 6 & 7 \\
\hline Was sufficiently responsive to our questions and problems we ran in to & 1 & 2 & 3 & 4 & 5 & 6 & 7 \\
\hline Stimulated us to report the results and progress monthly & 1 & 2 & 3 & 4 & 5 & 6 & 7 \\
\hline
\end{tabular}

\section{Achievability}

Dückers ML, Wagner C, Groenewegen PP (2008) Developing and testing an instrument to measure the presence of conditions for successful implementation of quality improvement collaboratives. BMC Health Serv Res 8, 172.

\begin{tabular}{|c|c|c|c|c|c|c|c|}
\hline \multirow[b]{2}{*}{ Collaborative targets are achievable } & \multicolumn{4}{|c|}{ Strongly disagree } & \multicolumn{3}{|c|}{ Strongly agree } \\
\hline & 1 & 2 & 3 & 4 & 5 & 6 & 7 \\
\hline Program management made clear how to achieve collaborative targets & 1 & 2 & 3 & 4 & 5 & 6 & 7 \\
\hline $\begin{array}{l}\text { Program management offered a standardised set of indicators to monitor } \\
\text { progress and compare results }\end{array}$ & 1 & 2 & 3 & 4 & 5 & 6 & 7 \\
\hline Program management offered good practices and evidence on achievable results & 1 & 2 & 3 & 4 & 5 & 6 & 7 \\
\hline
\end{tabular}




\section{Challenging targets}

Dückers ML, Wagner C, Groenewegen PP (2008) Developing and testing an instrument to measure the presence of conditions for successful implementation of quality improvement collaboratives. BMC Health Serv Res 8, 172.

\begin{tabular}{|c|c|c|c|c|c|c|c|}
\hline \multirow[b]{2}{*}{$\begin{array}{l}\text { Program management set high expectations with } \\
\text { regard to performance and improvement possibilities }\end{array}$} & \multicolumn{4}{|c|}{ Strongly disagree } & \multicolumn{3}{|c|}{ Strongly agree } \\
\hline & 1 & 2 & 3 & 4 & 5 & 6 & 7 \\
\hline
\end{tabular}

\section{Measurability}

Dückers ML, Wagner C, Groenewegen PP (2008) Developing and testing an instrument to measure the presence of conditions for successful implementation of quality improvement collaboratives. BMC Health Serv Res 8, 172.

\begin{tabular}{|c|c|c|c|c|c|c|c|}
\hline \multirow[b]{2}{*}{ Progress is measured continuously } & \multicolumn{4}{|c|}{ Strongly disagree } & \multicolumn{3}{|c|}{ Strongly agree } \\
\hline & 1 & 2 & 3 & 4 & 5 & 6 & 7 \\
\hline Timely and accurate progress information was available at all times & 1 & 2 & 3 & 4 & 5 & 6 & 7 \\
\hline Measuring indicators helps to monitor progress & 1 & 2 & 3 & 4 & 5 & 6 & 7 \\
\hline There were clear agreements on measuring central indicators & 1 & 2 & 3 & 4 & 5 & 6 & 7 \\
\hline
\end{tabular}

\section{Quality improvement commitment}

Shortell SM, O'Brien JL, Carman JM, et al. (1995) Assessing the impact of continuous quality improvement/total quality management: concept versus implementation. Health Serv Res 30, 377-401.

\begin{tabular}{|c|c|c|c|c|c|}
\hline \multirow{2}{*}{ Agree } & \multicolumn{2}{|c|}{$\begin{array}{l}\text { Strongly } \\
\text { disagree }\end{array}$} & \multicolumn{2}{|c|}{ Strongly agree } & \\
\hline & & & & & \\
\hline Staff is involved in developing plans for improving quality & 1 & 2 & 3 & 4 & 5 \\
\hline Staff is given the opportunity to improve quality & 1 & 2 & 3 & 4 & 5 \\
\hline $\begin{array}{l}\text { Staff has the authority to correct problems in their area when quality standards are not } \\
\text { being met }\end{array}$ & 1 & 2 & 3 & 4 & 5 \\
\hline Staff is supported when they take necessary risks to improve quality & 1 & 2 & 3 & 4 & 5 \\
\hline $\begin{array}{l}\text { The organisation has an effective system for employees to make suggestions to } \\
\text { management on how to improve quality }\end{array}$ & 1 & 2 & 3 & 4 & 5 \\
\hline $\begin{array}{l}\text { Staff is given education and training in how to identify and act on quality improvement } \\
\text { opportunities }\end{array}$ & 1 & 2 & 3 & 4 & 5 \\
\hline Staff is given the needed education and training to improve job skills and performance & 1 & 2 & 3 & 4 & 5 \\
\hline $\begin{array}{l}\text { Staff is rewarded and recognised (e.g., financially and/or otherwise) for improving } \\
\text { quality }\end{array}$ & 1 & 2 & 3 & 4 & 5 \\
\hline
\end{tabular}

\section{Organisational support}

RAND (2010) Improving Chronic Illness Care Evaluation. Healthcare Organization Survey for Breakthrough Series (BTS) Team members.

\begin{tabular}{|c|c|c|c|c|c|c|c|}
\hline \multirow[b]{2}{*}{ Senior management pays attention to the activities of the improvement team } & \multicolumn{4}{|c|}{ Strongly disagree } & \multicolumn{3}{|c|}{ Strongly agree } \\
\hline & 1 & 2 & 3 & 4 & 5 & 6 & 7 \\
\hline Senior management acted as coach to our improvement team & 1 & 2 & 3 & 4 & 5 & 6 & 7 \\
\hline Senior management encouraged staff to improve their performance & 1 & 2 & 3 & 4 & 5 & 6 & 7 \\
\hline Senior management provides good feedback on the work of our improvement team & 1 & 2 & 3 & 4 & 5 & 6 & 7 \\
\hline Senior management was open for criticism & 1 & 2 & 3 & 4 & 5 & 6 & 7 \\
\hline Senior management gave us time to reflect up on our work & 1 & 2 & 3 & 4 & 5 & 6 & 7 \\
\hline Senior management gave us time to try new working methods & 1 & 2 & 3 & 4 & 5 & 6 & 7 \\
\hline
\end{tabular}




\begin{tabular}{|c|c|c|c|c|c|c|c|}
\hline \multirow[b]{2}{*}{ I am satisfied about the way senior management supported our team } & \multicolumn{4}{|c|}{ Strongly disagree } & \multicolumn{3}{|c|}{ Strongly agree } \\
\hline & 1 & 2 & 3 & 4 & 5 & 6 & 7 \\
\hline Our team had enough time to implement the changes & 1 & 2 & 3 & 4 & 5 & 6 & 7 \\
\hline Our team had enough manpower to execute the project & 1 & 2 & 3 & 4 & 5 & 6 & 7 \\
\hline Our team had enough resources to make the project successful & 1 & 2 & 3 & 4 & 5 & 6 & 7 \\
\hline Our team members had the skills necessary to make the project successful & 1 & 2 & 3 & 4 & 5 & 6 & 7 \\
\hline
\end{tabular}

\section{Organisational culture}

Zammuto RF, Gifford G, Goodman EA (2000) Managerial ideologies, organisation culture and the outcomes of innovation: a competing values perspective. In The Handbook of Organizational Culture and Climate (Ashkanasy NM, Wilderom C \& Peterson MF eds). Sage Publications, Inc., Thousand Oaks, CA.

Shortell SM, O'Brien JL, Carman JM, et al. (1995) Assessing the impact of continuous quality improvement/total quality management: concept versus implementation. Health Serv Res 30, 377-401.

\section{Instructions}

These questions relate to the type of organisation that your institution is most like. Each of these items contains four descriptions of healthcare organisations. Please distribute 100 points among the four descriptions depending on how similar the description is to your organisation. None of these descriptions is any better than the others; they are just different. For each question, please use all 100 points. For example: In question 1, if Organization A seems very similar to mine, B seems somewhat similar, and C and $D$ do not seem similar at all, I might give 70 points to $A$ and the remaining 30 points to $B$. Please note that these questions pertain to the overall organisation of which you are a part, not to your individual team or unit.

\section{Organisation character (please distribute 100 points)}

1. Organisation A is a very personal place. It is a lot like an extended family. People seem to share a lot of themselves.

2. Organisation B is a very dynamic and entrepreneurial place. People are willing to stick their necks out and take risks.

3. Organisation $\mathrm{C}$ is a very formalized and structured place. Bureaucratic procedures generally govern what people do.

4. Organisation D is very production oriented. A major concern is with getting the job done. People aren't very personally involved.

\section{Total $=100$ points}

\section{Organisation's managers (please distribute 100 points)}

5. Managers in organisation A are warm and caring. They seek to develop employees' full potential and act as their mentors or guides.

6. Managers in organisation B are risk-takers. They encourage employees to take risks and be innovative.

7. __ Managers in organisation C are rule-enforcers. They expect employees to follow established rules, policies, and procedures.

8. Managers in organisation D are coordinators and coaches. They help employees meet the organisation's goals and objectives.

Total $=100$ points

Organisation cohesion (please distribute 100 points)

9. The glue that holds organisation A together is loyalty and tradition. Commitment to this organisation runs high.

10. The glue that holds organisation B together is commitment to innovation and development. There is an emphasis on being first.

11. The glue that holds organisation $\mathrm{C}$ together is formal rules and policies. Maintaining a smooth running operation is important here.

12. The glue that holds organisation D together is the emphasis on tasks and goal accomplishment. A production orientation is commonly shared.

Total $=100$ points

\section{Organisation emphases (please distribute 100 points)}

13. organisation A emphasizes human resources. High cohesion and morale in the organisation are important.

14. organisation B emphasizes growth and acquiring new resources. Readiness to meet new challenges is important. 
15. organisation $\mathrm{C}$ emphasizes permanence and stability. Efficient, smooth operations are important.

16. organisation D emphasizes competitive actions and achievement. Measurable goals are important.

Total $=100$ points

Organisation rewards (please distribute 100 points)

17. organisation A distributes its rewards fairly equally among its members. It's important that everyone from top to bottom be treated as equally as possible.

18. organisation $\mathrm{B}$ distributes its rewards based on individual initiative. Those with innovative ideas and actions are most rewarded.

19. organisation $\mathrm{C}$ distributes its rewards based on rank. The higher you are, the more you get.

20. organisation D distributes its rewards based on the achievement of objectives. Individuals who provide leadership and contribute to attaining the organisation's goals are rewarded.

Total $=100$ points

Innovative culture

Caldwell DF, O'Reilly CA (2003) The determinants of team-based innovation in organisations. The role of social influence. Small Group Research 34, 497-517.

Strating MMH, Nieboer AP (2010) Norms for creativity and implementation in healthcare teams: testing the group innovation inventory. International Journal for Quality in Health Care 6, 1-8.

\begin{tabular}{|c|c|c|c|c|}
\hline \multirow[b]{2}{*}{ Risk taking is encouraged around here } & \multicolumn{3}{|c|}{ Strongly disagree } & $\begin{array}{l}\text { Strongly } \\
\text { agree }\end{array}$ \\
\hline & 1 & 2 & 3 & 4 \\
\hline Management provides rewards and recognition for innovation and trying new things & 1 & 2 & 3 & 4 \\
\hline Mistakes are a normal part of trying something new & 1 & 2 & 3 & 4 \\
\hline People have great freedom to act to make necessary changes around here & 1 & 2 & 3 & 4 \\
\hline $\begin{array}{l}\text { The attitude around here is that when you are trying new things, mistakes are a normal } \\
\text { part of the job }\end{array}$ & 1 & 2 & 3 & 4 \\
\hline In our group, there is a great deal of openness in sharing information & 1 & 2 & 3 & 4 \\
\hline People in our group encourage each other to try new things & 1 & 2 & 3 & 4 \\
\hline Decisions in our group are made quickly & 1 & 2 & 3 & 4 \\
\hline Management encourages people to try new things. & 1 & 2 & 3 & 4 \\
\hline Members of our group listen carefully to the views of others & 1 & 2 & 3 & 4 \\
\hline $\begin{array}{l}\text { In our group we expect others to take initiative and get things done } \\
\text { even if a person is not formally responsible }\end{array}$ & 1 & 2 & 3 & 4 \\
\hline Our group is flexible and adapts quickly to new opportunities. & 1 & 2 & 3 & 4 \\
\hline In our group we try to reach a consensus about important decisions & 1 & 2 & 3 & 4 \\
\hline Once a decision is made, we implement it quickly & 1 & 2 & 3 & 4 \\
\hline Our group has sufficient autonomy to implement new ideas without clearance from above. & 1 & 2 & 3 & 4 \\
\hline People in this organisation are willing to try new things & 1 & 2 & 3 & 4 \\
\hline It may go wrong when trying to grant wishes of individual clients & 1 & 2 & 3 & 4 \\
\hline $\begin{array}{l}\text { In this organisation we are always looking for other ways to organise our work } \\
\text { in order to provide better care }\end{array}$ & 1 & 2 & 3 & 4 \\
\hline
\end{tabular}

\section{Commitment to change}

Vroom VH (1995) Work and Motivation. Jossey-Bass, Co., San Francisco, CA.

\begin{tabular}{|c|c|c|c|c|c|c|c|}
\hline Exerting effort (e.g., time and resources) will & Strongly disagree & & & & & & Strongly agree \\
\hline Help you implement changes in care & 1 & 2 & 3 & 4 & 5 & 6 & 7 \\
\hline Success in implementing changes in care & Strongly disagree & & & & & & Strongly agree \\
\hline Help you improve quality of care for patients & 1 & 2 & 3 & 4 & 5 & 6 & 7 \\
\hline
\end{tabular}




\begin{tabular}{|c|c|c|c|c|c|c|c|}
\hline Exerting effort (e.g., time and resources) will & Strongly disagree & & & & & & Strongly agree \\
\hline Help you improve patient satisfaction with their care & 1 & 2 & 3 & 4 & 5 & 6 & 7 \\
\hline Help you improve productivity/efficiency & 1 & 2 & 3 & 4 & 5 & 6 & 7 \\
\hline Help improve patient clinical outcomes & 1 & 2 & 3 & 4 & 5 & 6 & 7 \\
\hline Help you involve patients with their own care & 1 & 2 & 3 & 4 & 5 & 6 & 7 \\
\hline Help improve continuity of care & 1 & 2 & 3 & 4 & 5 & 6 & 7 \\
\hline Allow you opportunities to use your skills and abilities better & 1 & 2 & 3 & 4 & 5 & 6 & 7 \\
\hline $\begin{array}{l}\text { Help you get recognition (i.e., praise, promotion, etc.) from your } \\
\text { superiors }\end{array}$ & 1 & 2 & 3 & 4 & 5 & 6 & 7 \\
\hline Help you feel that you have accomplished something worthwhile & 1 & 2 & 3 & 4 & 5 & 6 & 7 \\
\hline Exerting effort (e.g., time and resources) will & Strongly disagree & & & & & & Strongly agree \\
\hline Help you to adopt the PDSA improvement process & 1 & 2 & 3 & 4 & 5 & 6 & 7 \\
\hline Success in adopting the PDSA improvement process will & Strongly disagree & & & & & & Strongly agree \\
\hline Enable your team to make changes that improve the processes of care & 1 & 2 & 3 & 4 & 5 & 6 & 7 \\
\hline Enable process changes to be spread to other parts of the organisation & 1 & 2 & 3 & 4 & 5 & 6 & 7 \\
\hline Enable the team to gain support for process changes & 1 & 2 & 3 & 4 & 5 & 6 & 7 \\
\hline $\begin{array}{l}\text { Enable your team to adapt the collaborative improvement methods } \\
\text { to their needs }\end{array}$ & 1 & 2 & 3 & 4 & 5 & 6 & 7 \\
\hline How important are the following to you? & Strongly disagree & & & & Strongly agree & & \\
\hline Improving quality of care for patients & 1 & 2 & 3 & 4 & 5 & & \\
\hline Improving patient satisfaction with their care & 1 & 2 & 3 & 4 & 5 & & \\
\hline Improving productivity/efficiency & 1 & 2 & 3 & 4 & 5 & & \\
\hline Improving patient clinical outcomes & 1 & 2 & 3 & 4 & 5 & & \\
\hline Involving patients with their own care & 1 & 2 & 3 & 4 & 5 & & \\
\hline Improving continuity of care & 1 & 2 & 3 & 4 & 5 & & \\
\hline Having opportunities to use your skills and abilities better & 1 & 2 & 3 & 4 & 5 & & \\
\hline Getting recognition (i.e., praise, promotion, etc.) from your superiors & 1 & 2 & 3 & 4 & 5 & & \\
\hline Feeling that you have accomplished something worthwhile & 1 & 2 & 3 & 4 & 5 & & \\
\hline Making changes that improve the processes of care & 1 & 2 & 3 & 4 & 5 & & \\
\hline Spreading process changes to other parts of the organisation & 1 & 2 & 3 & 4 & 5 & & \\
\hline Gaining support for process changes & 1 & 2 & 3 & 4 & 5 & & \\
\hline Adapting collaborative improvement methods to your team's needs & 1 & 2 & 3 & 4 & 5 & & \\
\hline
\end{tabular}

The Journal of Clinical Nursing (JCN) is an international, peer reviewed journal that aims to promote a high standard of clinically related scholarship which supports the practice and discipline of nursing.

For further information and full author guidelines, please visit JCN on the Wiley Online Library website: http:// wileyonlinelibrary.com/journal/jocn

\section{Reasons to submit your paper to JCN:}

High-impact forum: one of the world's most cited nursing journals, with an impact factor of 1.118 - ranked 30/95 (Nursing (Social Science)) and 34/97 Nursing (Science) in the 2011 Journal Citation Reports ${ }^{\circledR}$ (Thomson Reuters, 2011)

One of the most read nursing journals in the world: over 1.9 million full text accesses in 2011 and accessible in over 8000 libraries worldwide (including over 3500 in developing countries with free or low cost access).

Early View: fully citable online publication ahead of inclusion in an issue.

Fast and easy online submission: online submission at http://mc.manuscriptcentral.com/jcnur.

Positive publishing experience: rapid double-blind peer review with constructive feedback.

Online Open: the option to make your article freely and openly accessible to non-subscribers upon publication in Wiley Online Library, as well as the option to deposit the article in your preferred archive. 